\title{
Content revision and case study in Metallic Materials
}

\author{
Zhizhong Yuan ${ }^{1, a}$, Hua Cheng ${ }^{2, b}$, Qixun Dai ${ }^{1, c}$ and Xiaonong Cheng ${ }^{1, d}$ \\ ${ }^{1}$ School of Materials Science and Engineering, Jiangsu University, Zhenjiang, P.R. China \\ ${ }^{2}$ School of Management, Jiangsu University, Zhenjiang, P.R. China

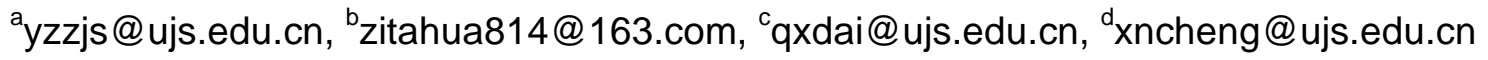

Keywords: College Education, Materials Science and Engineering, Metallic Materials, Case Study Abstract. Advices on the content revision and teaching method of Metallic Materials are proposed in this paper. The basic concepts about the defects from steelmaking and hot processing and their effects on the subsequent processing and final properties should be added into the textbook of Metallic Materials. As for the teaching method, multimedia teaching about knowledge points is far from enough. Case study should be introduced into Metallic Materials. Cases are elaborately designed and based on engineering applications, which can build the connection between different knowledge points and reinforce the students' understanding and application of knowledge.

\section{Introduction}

Metallic Materials is one of the key courses for students of Materials Science and Engineering (MSE), especially for those majoring in Metallic Materials Engineering (MME). The content of this course is mainly focused on the theoretical and application knowledge directly related to the academic and industrial work for students after graduation. Moreover, this course may be selected by the students with Mechanical and other engineering backgrounds.

\section{Content revision}

The main content and the relations with other courses of Metallic Materials are show in Fig. 1. The lower part of Fig. 1 demonstrates that Metallic Materials is based on other courses. As for the students majoring in MME are concerned, they firstly learn Fundamentals of MSE and then other courses such as Principles of Heat Treatment, Techniques of Heat Treatment and Mechanical Properties, etc. The students also learn some courses from the discipline of Materials Forming and Processing, such as Casting, Pressure Processing and Welding, etc. Therefore, Metallic Materials is usually arranged as the last obligatory course for students who major in MME.

The upper part of the Fig. 1 shows the main content of Metallic Materials, which includes the composition, processing, structure/phase, property and behavior/environment. All these aspects support the engineering application of metallic materials.

Many Metallic Materials textbooks [1,2] include three main parts: alloying theory, metallic materials for engineering application and advanced metallic materials. The first part covers the principles of alloying elements into $\mathrm{Fe}$ and their effects on the processing and mechanical properties of metallic materials. The second part includes many chapters based on the properties, applications of metallic materials such as tool steels, stainless steels and heat-resistant steels, etc. The third part deals with many kinds of materials with special composition or fabricated by special processing technology, such as shape-memory alloy, amorphous metal and metal-matrix composite, etc. 


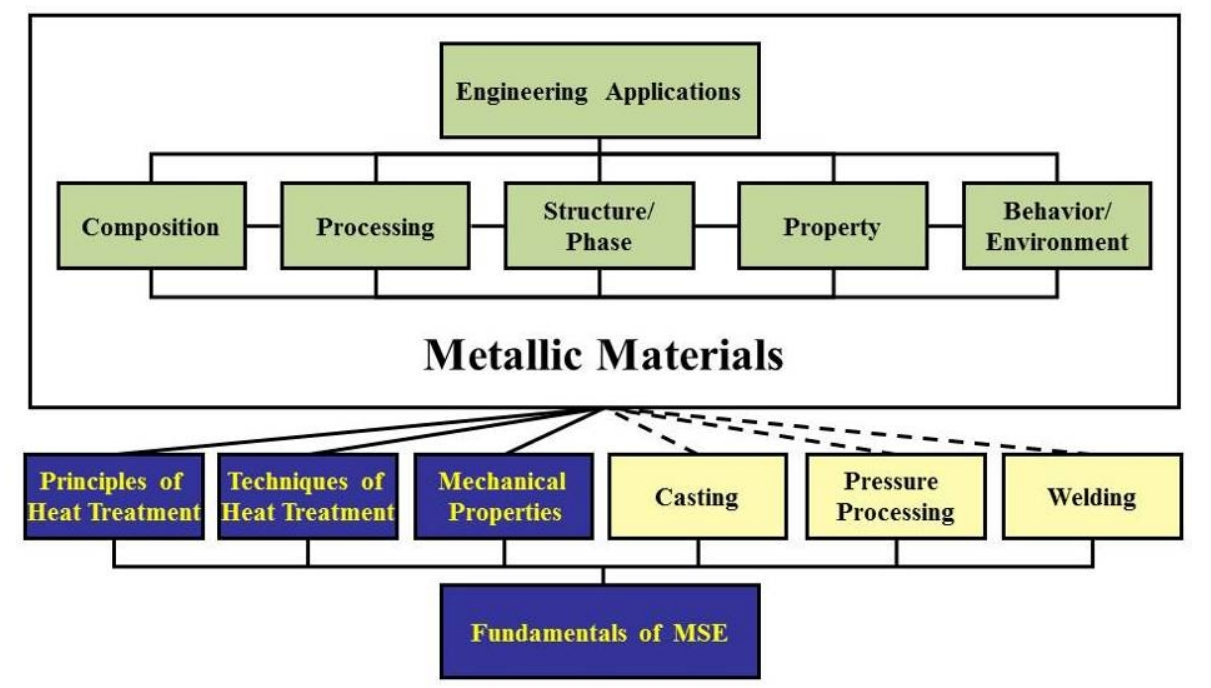

Fig. 1 Contents of Metallic Materials and its connections with other courses

The alloying theory is the most important content of Metallic Materials and it is the only chapter that deals with theory. However, most content of this course is for the engineering applications of metallic materials. Metal parts or components are the most typical products and most common application of metal materials in many industries. So, most of discussion about engineering applications in Metallic Materials is centered on metal components. As can be seen from Fig. 2, the solid-line arrow shows the right sequence to products (metal components) fabrication, i.e. Alloying Theory, Steelmaking \& Hot Processing and Heat Treatment \& Machining. However, many textbooks of Metallic Materials arrange the teaching content following the dashed-line arrow in Fig. 2. The content of Steelmaking \& Hot Processing is usually overlooked or only touched at the sallow surface, resulting in that the main content concerning engineering application about the metal components fabrication is almost focused on Heat Treatment \& Machining.

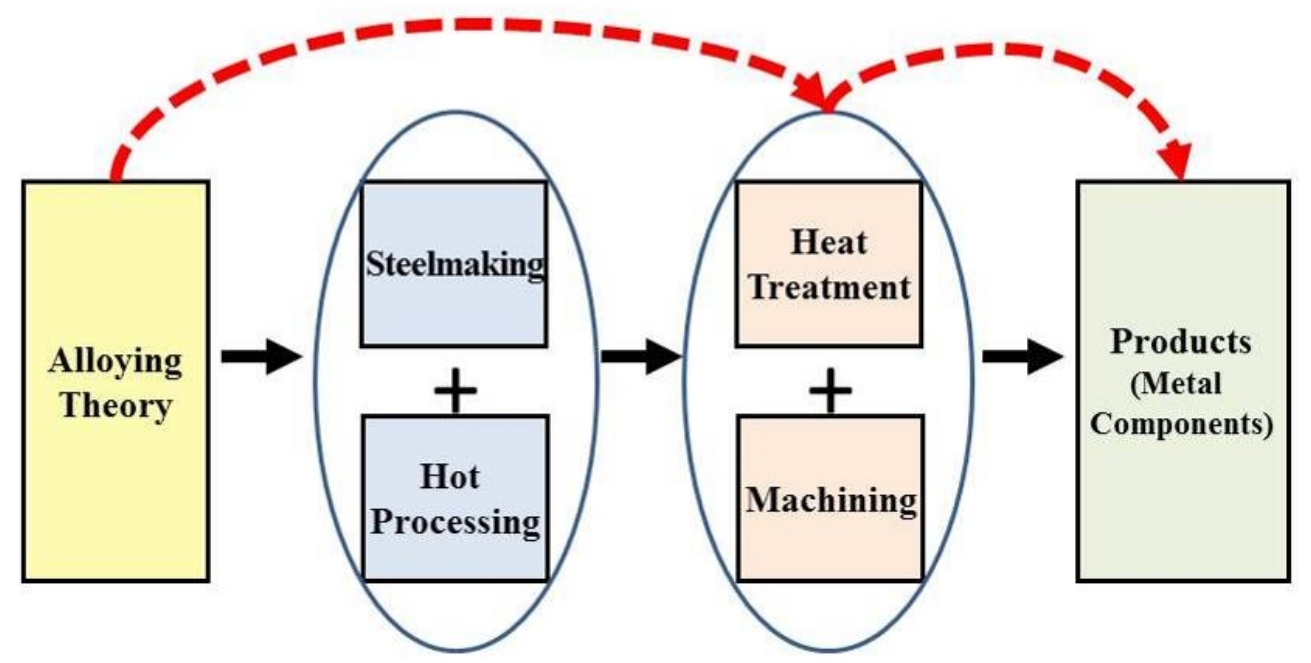

Fig. 2 The sequence of four major contents based on the fabrication of metal products. The solid-line arrows show the correct connection and sequence. The dashed-line arrows show the actual teaching situation

In fact, according to the real industrial situation, the Steelmaking \& Hot Processing should not be missed. As can be seen from the Fig. 3, the most acceptable viewpoint about the quality of metal components is decided by material, heat treatment and machining, which accounts for $50 \%, 30 \%$ and $20 \%$, respectively. As for the material, it mainly contains technologies such as steelmaking and hot 
processing. The defects of them will finally determine the property and behavior of metal components. So, they are absolutely important.

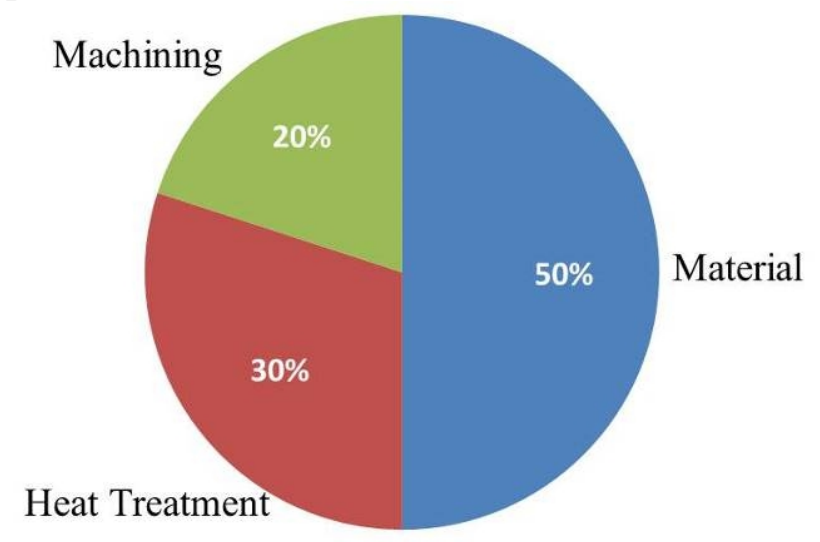

Fig. 3 Decisive factors and their proportion to the final quality of metal components

Therefore, contents about the basic concepts of steelmaking and hot processing should be made up in the textbooks and in the classrooms during teaching for Metallic Materials. Here are two examples. The first one concerns about the impurity element of $S$. The well-known hazard of $S$ is the formation of $\mathrm{MnS}$ inclusions. So far, this single sentence is far from enough. The students should be given some visual impression and explained about how $\mathrm{MnS}$ affects the mechanical properties of metal materials. So some key information should be made up as follows. The microstructure of a MnS by scanning electron microscope (SEM) is added, as shown in Fig. 4 (a)[3]. The diameter of this inclusion is about 5 m. Fig. 4 (b) is the composition analysis by energy dispersive spectrometer (EDS) of the inclusion in Fig. 4 (a), which verifies the inclusion is MnS [3]. In Fig. 4 (a), this specimen is in situ tensile tested to an elongation of $2 \mathrm{~mm}$ in SEM. It can be seen that the inclusion is in a crack. On the other word, the crack is actually resulting from this inclusion. Therefore, the inclusion is greatly harmful to mechanical properties. From this example, students can easily understand the microstructure of $\mathrm{MnS}$ and its effects on mechanical properties. They also learn how to characterize inclusions formed by impurity elements.
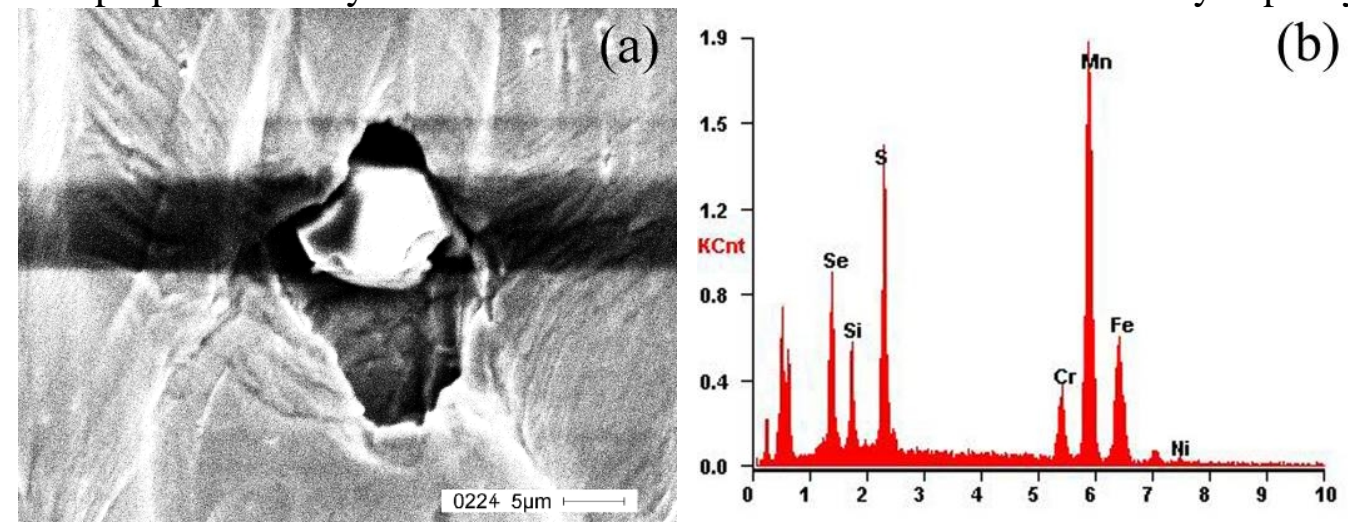

Fig. 4 (a) Microstructure and (b) the EDS result of the inclusion [3]

Another example is about the effects of hot processing on the subsequent processing procedures. In Fig. 5 (a), the metal parts are fabricated by cutting, drilling and bending to hot rolled low-carbon metal sheets, which have the strip-like microstructure as shown in Fig. 5 (b). The bright strips are Pearlite and the dark ones are Ferrite. This special microstructure will definitely lead to mechanically anisotropy and should be always kept in mind when designing metal parts. The direction of the force should be vertical to strips to avoid early-stage failure of long cracks along the strips. 

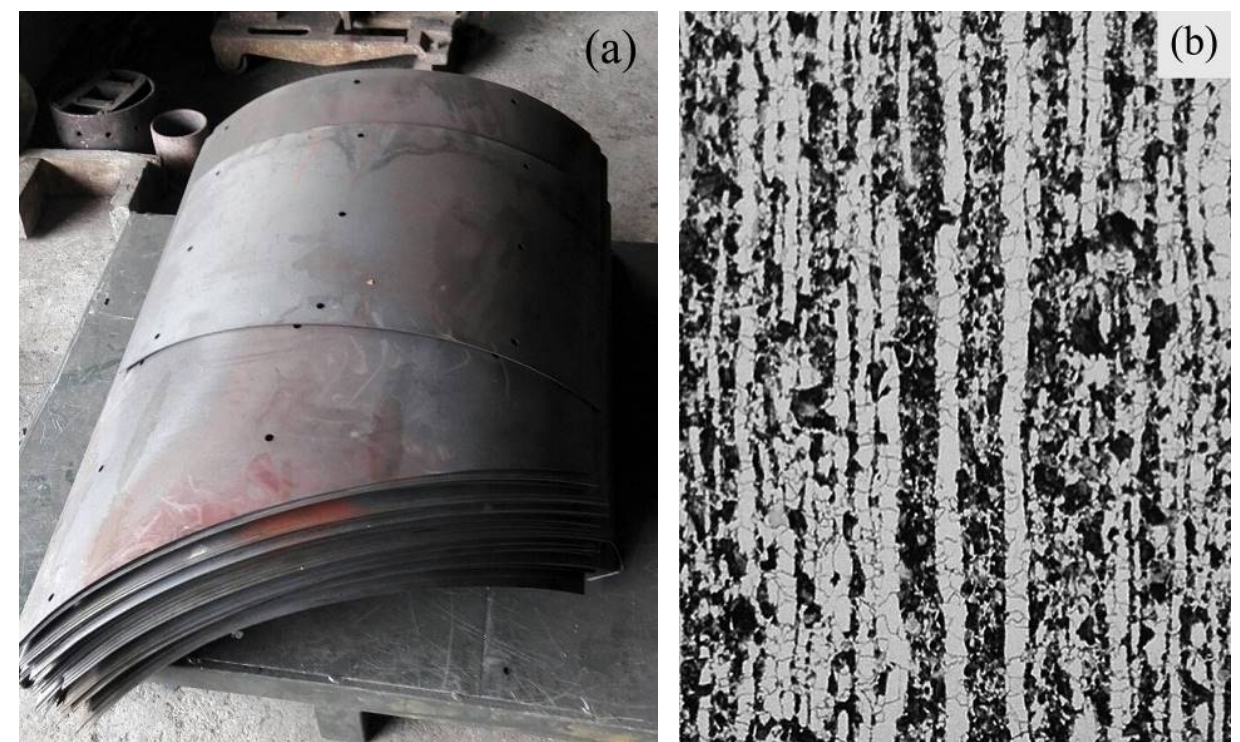

Fig. 5 (a) Metal sheets manufactured by hot rolling; (b) metallograph of the metal sheet

There are many other examples of defects during steelmaking and hot processing, which have great influence on the subsequent processing procedures. For example, the metal rods by casting of naturally crystallization usually have the inclusion segregation at the center, the cross-sectional end faces of which cannot be made as the service faces of metal components; The continuous casting and rolling can greatly improve the fabrication efficiency and hardness of metal sheets, but more impurities may be introduced at the surfaces of the sheets; The defects such as carbide segregation will seriously decrease the lifetime of bearings and they can only be eliminated by techniques such as forging and diffusion annealing for a long time.

If the basic knowledge of defects resulted from the steelmaking and hot processing was not introduced, students would probably confront great confusion in practical work. By introducing this part of knowledge, students will pay attention to the quality of raw material, deeply understand the differences between raw materials fabricated by different steelmaking and hot processing techniques and learn the limitations of heat treatment and machining for the enhancement to the final quality of metal components.

\section{Case study}

Pictures and videos can greatly improve the understanding of students to knowledge points. But this is far from enough. What the students mostly need is to grasp the knowledge and the ability to solve practical engineering problems. Therefore, case study can achieve better results.

The following is a summary of a case based on many years of teaching experience. As for the impurity element of $\mathrm{P}$, its main hazard is the embrittlement to metals, i.e. strongly elevating the ductile to brittle transition temperature (DBTT). In the classroom, a discussion is proposed: except from the decrease of the $\mathrm{P}$ during steel smelting process, is there any other method to avoid the embrittlement based on the existing content of P?

Then a case is proposed based on a project we did for a company. A transmission shaft is made of 42CrMo, which is a $\mathrm{Cr}$ and Mo lightly-alloyed plain carbon steel and its composition is shown in Table 1. As for the content of $\mathrm{P}$, it is less than $0.08 \mathrm{wt} . \%$. The shaft fractured as serving at low temperature. Its heat treatment was quenching from $850{ }^{\circ} \mathrm{C}$ and tempering at about $400{ }^{\circ} \mathrm{C}$. We changed the original heat treatment process as follows. Firstly, the shaft is quenched $\left(850{ }^{\circ} \mathrm{C}\right.$ for $1 \mathrm{~h}$, cooled in oil) and tempered $\left(550^{\circ} \mathrm{C}\right.$ for $\left.3 \mathrm{~h}\right)$ based on the parameters of Table 2 . The hardness of the shaft is about 32 40 HRC. More importantly, the microstructure of the shaft becomes a uniform tempered Sorbite and the grains are refined to some extent by this heat treatment process. It is well known that the refined grains will decrease the DBTT. 
Table 1. Composition of 42CrMo

\begin{tabular}{cccccccc}
\hline Element & $\mathrm{C}$ & $\mathrm{Cr}$ & $\mathrm{Mo}$ & $\mathrm{Mn}$ & $\mathrm{Si}$ & $\mathrm{P}$ & $\mathrm{Fe}$ \\
\hline $\begin{array}{c}\text { Composition } \\
(\text { wt. \%) }\end{array}$ & 0.43 & 1.09 & 0.20 & 0.67 & 0.31 & $<0.08$ & Balance \\
\hline
\end{tabular}

Table 2. Heat treatment parameters of 42CrMo [4]

\begin{tabular}{cccc}
\hline Parameter & $\mathrm{Ac}_{1}$ & $\mathrm{Ac}_{3}$ & $\mathrm{Ms}$ \\
\hline Temperature $\left({ }^{\circ} \mathrm{C}\right)$ & 730 & 800 & 310 \\
\hline
\end{tabular}

The second step is to change the impurity $\mathrm{P}$ into an enforcement factor. The mechanism is shown in the Fe-P binary phase diagram, as shown in Fig. 6. It can be seen that the solubility of $\mathrm{P}$ in $\quad$-Ferrite is much higher than that in -Austenite. For example, the solubility of $\mathrm{P}$ in -Ferrite is about 0.68 wt.\% whereas that in -Austenite is only $0.28 \mathrm{wt} \%$ at $1150{ }^{\circ} \mathrm{C}$. P only dissolves in -Ferrite at temperature lower than $900{ }^{\circ} \mathrm{C}$ and the content of $\mathrm{P}$ is lower than $0.08 \mathrm{wt} . \%$. Moreover, it can be seen form Fig. 7 that $\mathrm{P}$ is the most effective element to strengthen the -Ferrite. If the $\mathrm{P}$ only dissolved in -Ferrite, then -Ferrite would be enhanced and the -Austenite will not be embrittled. So, a quench process at $750{ }^{\circ} \mathrm{C}$ is performed. At this temperature, the $42 \mathrm{CrMo}$ is at + binary phase region and $\mathrm{P}$ will diffuse into phase. Moreover, the grains are further refined by this process. Then the shaft is quenched into oil and tempered. The phase remains unchanged whereas the phase transforms into tempered Martensite. After this two-step heat treatment, the shaft can service at temperature lower than $-20{ }^{\circ} \mathrm{C}$.

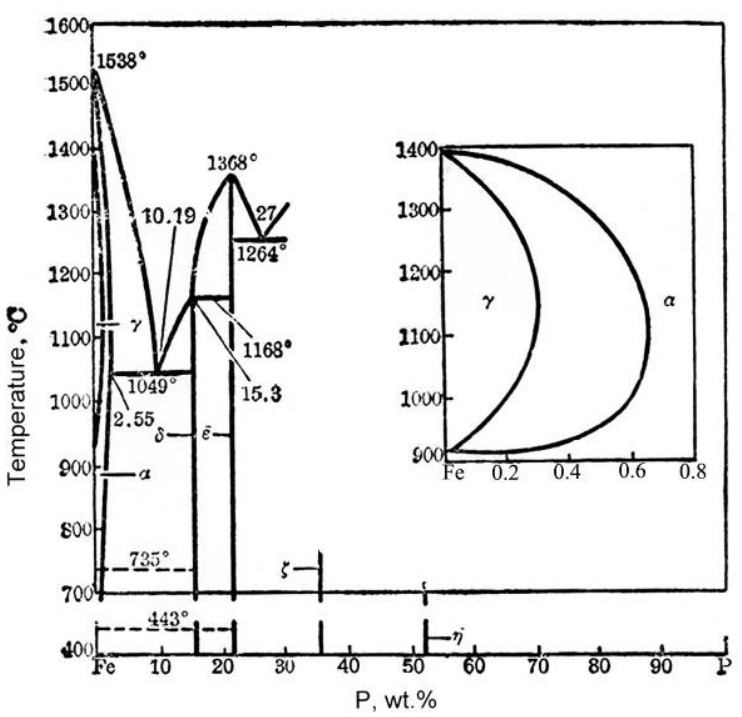

Fig. 6 Fe-P binary phase diagram [5]

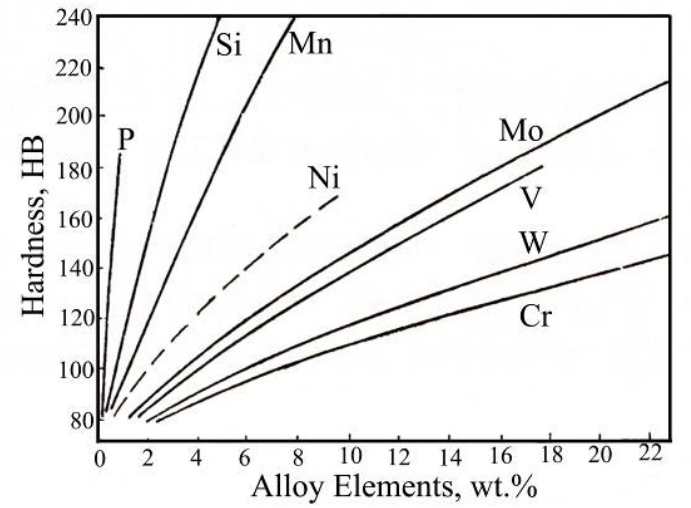

Fig. 7 Enhancement of different alloy elements to

-Ferrite [5] 
In this case, knowledge points such as grain refinement enhancement, phase diagram and heart treatment are integrated. Students can easily understand the connections between different knowledge points and their ability to solve practical problems is enhanced.

In the teaching practice, such case received great attention. Students reflect that case study is fascinating. It is much closer to engineering applications and valuable for their future work after graduation.

In the near future, the knowledge points and corresponding cases will be separated as the online videos and classroom discussions, respectively. This kind of MOOCs will help both the students and the teachers. Courses will be easier to learn for students and the teachers will get a clearer picture about how deep and solid the students understand the knowledge points [6-10].

\section{Conclusions}

It is emphasized that the content about steelmaking and hot processing is vital and should be made up in Metallic Materials. On the other hand, the well designed and prepared cases can help the students to make connections between different knowledge points and link the theory to practice. This is especially important for courses, such as Metallic Materials, focusing on the engineering applications.

\section{Acknowledgements}

This work was financially supported by the Top-notch Academic Programs Project of Jiangsu Higher Education Institutions (TAPP) and Study and Application of Inquiry Case Study in College Education (555116003).

\section{References}

[1] Qixun Dai: Metallic Materials (Chemistry Industry Press, China 2012) (In Chinese)

[2] Jiuba Wen: Metallic Materials (China Machine Press, China 2013) (In Chinese)

[3] Zhizhong Yuan, Qixun Dai, Xiaonong Cheng, Kangmin Chen, Li Pan and Andong Wang: Mater. Char. Vol. 56 (2006), p. 79

[4] Weiping Ye and Qintie Zhang: Handbook of heat treatment data (Second edition) (China Machine Press, China 2010) (In Chinese)

[5] E. Hornbogen: Physical Metallurgy (North Holland Publication Co., Holland 1970)

[6] R. Kop, H. Foumier and J.S. Fai: Inter. Rev. Res. Open \& Dist. Learn. Vol. 12 (2011), p. 74

[7] K.F. Hew and W.S. Cheung: Edu. Res. Rev. Vol. 12 (2014), p. 45

[8] M.H. Baturay: Proc.-Soc. \& Behav. Sci. Vol. 174 (2015), p. 427

[9] K.M. Alraimi, H. Zo and A.P. Ciganek: Comput. \& Edu. Vol. 80 (2015), p. 28

[10]T. Brahimi and A. Sarirete: Comput. Hum. Behav. Vol. 51 (2015), p. 604 